\title{
Processos gerenciais de gestão de pessoas em empresas do setor da construção civil.
}

\section{Resumo}

A gestão de pessoas busca promover o êxito organizacional por meio do alinhamento dos esforços humanos. Esta pesquisa objetivou analisar como os processos gerenciais são aplicados na gestão de pessoas em empresas do setor da construção civil do norte paranaense. Desenvolveu-se uma pesquisa descritiva, um estudo de caso qualitativo. Os resultados demonstram que, nas empresas pesquisadas, destacam-se a promoção da capacitação e desenvolvimento por meio do programa de educação continuada, a liberdade de trabalho e a autonomia de cada colaborador dentro de sua função e a utilização de relatórios como balizador do bom andamento das relações entre as pessoas.

Palavras-chave: Gestão de Pessoas. Modelo de Excelência da Gestão. Processos Gerenciais.

\section{People management processes in company of sector of construction sector.}

\begin{abstract}
People management seeks to promote organizational success by aligning human efforts. This study aimed to analyze how management processes are applied in the management of people in companies in the construction sector of northern Paraná. Developed a descriptive research, a qualitative case study. The results show that the surveyed companies, we highlight the promotion of training and development through continuing education program, the freedom to work and the autonomy of each employee within their function and use as base reporting good progress of relations between people.
\end{abstract}

Keywords: People Management. Excellence Model Management. Managerial Process.

\footnotetext{
1 Coordenador Acadêmico do Curso de Administração da Faculdade Arthur Thomas. (kroncon@hotmail.com)

2 Professora na Faculdade Arthur Thomas. (marciaplang@hotmail.com)

3 Docente de Graduação e Pós-Graduação, Mestre em Administração - PPGA/UEL -Londrina/PR. (profaindiarabeltrame@hotmail.com)
} 


\section{Introdução}

$\mathrm{Na}$ atual configuração empresarial, se reconhece a importância das pessoas para o sucesso organizacional ao ponto de se comparar o potencial produtivo das organizações ao capital humano que as compõem. A definição do desempenho da organização em sua área de atuação depende do conhecimento dos empregados e de sua capacidade criatividade a serviço da empresa.

O ambiente corporativo assume perspectivas cada vez mais mundiais e apresenta, como característica essencial, a perspectiva de se transformar rapidamente (SARTORI; SILUK, 2011). Para os autores, a gestão eficaz de um negócio demanda dos profissionais saberes diversos: ampla visão do mercado; espírito empreendedor; definição de objetivos; bem como a capacidade de elaborar políticas e estratégias que apontem para o futuro.

Com foco em uma gestão eficaz de negócios, faz-se importante atentar para um dos mais complexos desafios organizacionais da atualidade: a diversidade da força de trabalho, que exige das empresas uma série de adaptações frente às diferenças dos indivíduos. Tal diversidade considera, dentre tantos fatores, as deficiências ou restrições físicas, as necessidades especiais, as etnias, o gênero, as crenças religiosas, a idade e a orientação sexual dos colaboradores da organização, que privilegiam uma gestão focada no indivíduo e nas dimensões humanas, psicológicas e sociais.

Diante de tantos desafios e do crescente entendimento da importância das pessoas para a efetivação do negócio de uma organização considera-se gestão de pessoas, na visão de França (2010), como a soma alinhada dos esforços humanos nas áreas estratégicas, de gerenciamento e de produção, com vistas a atingir os objetivos organizacionais e individuais.

O setor da construção civil se configura por meio de um cenário que se altera, na medida em que a economia brasileira se estabiliza, a globalização se instaura e os empresários do setor buscam soluções tecnológicas para a produção e o gerenciamento eficaz de seus processos, permitindo projeções de ganhos satisfatórios pela melhoria da capacidade produtiva, que proporciona a redução de custos e o aumento da produtividade (MDIC, 2003).

Apoiado na premissa de que as pessoas são fundamentais ao êxito organizacional, e que o setor da construção civil ocupa lugar de destaque na cadeia produtiva nacional, influenciando vários setores e empregando quantidade maciça de pessoas, questiona-se: como ocorrem os processos gerenciais aplicados na gestão de pessoas em empresas do setor da construção civil do norte paranaense? Nesse sentido, este estudo objetivou analisar como os processos gerenciais são aplicados na gestão de pessoas em empresas do setor da construção civil do norte paranaense. Mais especificamente, buscou-se: (i) compreender como o sistema de trabalho é elaborado e implementado pela organização; (ii) verificar como ocorrem os processos de capacitação e desenvolvimento dentro da organização; e (iii) desvelar como a qualidade de vida é praticada na organização pesquisada.

Este estudo justifica-se pelo entendimento da importância das pessoas como força de trabalho e agentes implementadores das estratégias e planos organizacionais, atribuindo competitividade às empresas no desafio do êxito organizacional frente à globalização dos mercados. A aplicação de um modelo de gestão de pessoas no setor de construção civil, que em 2001 representou um montante entre 6 a $9 \%$ do Produto Interno Bruto nacional (MDIC, 2003), possibilita o entendimento da influência humana neste processo produtivo de importância social expressiva na geração de empregos.

\section{Gestão de Pessoas}

Agestão de pessoas adquiriu uma temática de relevante importância frente às necessidades apresentadas pelo mundo contemporâneo, visto que é no interior das organizações que as 
pessoas passam a maior parte das suas vidas. Define-se gestão de pessoas, na perspectiva de GIL (2009, p. 17), como a "função gerencial que visa à cooperação das pessoas que atuam nas organizações para o alcance dos objetivos tanto organizacionais quanto individuais". Compreende-se gestão de pessoas como um conjunto das forças humanas voltadas para as atividades produtivas, gerenciais e estratégicas dentro de um ambiente organizacional (FRANÇA, 2010).

Nessa perspectiva a gestão de pessoas emerge como importante vertente no entendimento da participação humana na execução das atividades organizacionais, no sentido de se obter os resultados esperados (RONCON et al., 2013). Este conceito foi ampliado por Lacombe (2005) ao defender que essa participação diz respeito muito mais a uma finalidade do que a um cargo ou função exercidos no campo de ação das organizações.

Entende-se como um dos principais desafios da gestão de pessoas a busca do equilíbrio entre as dimensões do comportamento humano e os subsistemas da gestão de pessoas dentro da cultura de uma organização (KNAPIK, 2008), no qual os atores organizacionais apresentam formas particulares de desenvolver suas práticas que são combinadas e alteradas de acordo com seu desenvolvimento (RONCON et al., 2012).

Como a organização depende das pessoas para atingir seus objetivos, considera-se o gestor de pessoas o responsável pela interação entre os objetivos pessoais e organizacionais. Cada vez mais a gestão de pessoas ocupa uma posição estratégica dentro das organizações, e o gestor de pessoas passa a ter o papel de transmissor de uma cultura de aprendizagem, buscando estimular a geração de novas habilidades e conhecimento nos colaboradores (KNAPIK, 2008).

O gestor de pessoas, na perspectiva de Gil (2009), é um novo profissional, visto que se requer dele um conjunto de atitudes e práticas bastante diferenciadas em relação às que vinham sendo desenvolvidas num passado recente e mesmo na atualidade de algumas empresas. Considera-se o papel do gestor de pessoas como determinante para a manutenção da identidade organizacional (FLEURY, 1987; SCHEIN, 1987; SCHEIN, 2001; DIAS, 2003; RONCON et al., 2013).

Uma das características de trabalho deste novo profissional, que assume uma visão em longo prazo, direciona-se para as competências dos colaboradores (ALMEIDA et al., 2009), uma vez que busca suprir as necessidades organizacionais, atuais e futuras, por meio da aplicação de processos e atividades relativas a gestão de pessoas.

Os processos de suprimento, de manutenção, de desenvolvimento e de monitoramento são apresentados por Gil (2009) como atividades a serem desenvolvidas pelo gestor de pessoas. O autor atribui, ainda, a este profissional, os papéis de analista de cargos e salários, de motivador, de líder, bem como de negociador, de gestor da qualidade e de coach.

Em suma, depreende-se a gestão de pessoas como uma atividade profissional que exige pessoas especializadas para lhe fazer frente. Este gestor deve ter preparo interdisciplinar para desenvolver uma visão sistêmica da organização, com o objetivo de supri-la com o capital intelectual adequado ao seu modelo de negócio.

Infere-se, também, a necessidade de um gestor atento às implicações físicas, psicológicas e profissionais das atividades sobre as pessoas, capaz de intervir de forma pontual e proporcionar o alcance dos objetivos organizacionais, focando a satisfação do cliente, sem ignorar as aspirações dos indivíduos e suas demandas no trabalho e fora dele.

Modelo de Excelência em Gestão na Dimensão Pessoas

O Modelo de Excelência da Gestão (MEG) foi criado pela Fundação Nacional da Qualidade 
(FNQ) com o intuito de orientar as organizações na sua gestão e avaliá-las para, então, indicálas ao Prêmio Nacional da Qualidade (FNQ, 2008a). A característica mais relevante do MEG consiste na busca por estruturar e alinhar os fundamentos de excelência dos componentes de gestão, colocando toda a organização sob um mesmo ângulo de visão (FNQ, 2008c).

Quando aplicados, os fundamentos da excelência descritos no Quadro 1 proporcionam redução dos custos e aumento da produtividade, atribuindo competitividade à organização por meio de melhorias dos produtos e processos (FNQ, 2008a).

Quadro 1 - Fundamentos da excelência.

\begin{tabular}{|c|c|}
\hline \multicolumn{2}{|r|}{ Fundamentos da Excelência } \\
\hline $\begin{array}{l}\text { Pensamento } \\
\text { Sistêmico }\end{array}$ & $\begin{array}{l}\text { Entendimento das relações de interdependência entre os diversos componentes } \\
\text { de uma organização, bem como a organização e o ambiente externo. }\end{array}$ \\
\hline $\begin{array}{l}\text { Aprendizado } \\
\text { organizacional }\end{array}$ & $\begin{array}{l}\text { Busca e alcance de um novo patamar de conhecimento para a organização por } \\
\text { meio de percepção, reflexão, avaliação e compartilhamento de experiências. }\end{array}$ \\
\hline $\begin{array}{l}\text { Cultura de inova- } \\
\text { ção }\end{array}$ & $\begin{array}{l}\text { Promoção de um ambiente favorável à criatividade, experimentação e imple- } \\
\text { mentação de novas ideias que possam gerar um diferencial competitivo para a } \\
\text { organização. }\end{array}$ \\
\hline $\begin{array}{l}\text { Liderança e } \\
\text { constância de } \\
\text { propósitos }\end{array}$ & $\begin{array}{l}\text { Atuação, de forma aberta, democrática, inspiradora e motivadora das pessoas, } \\
\text { visando ao desenvolvimento da cultura da excelência, à promoção de relações } \\
\text { de qualidade e à proteção dos interesses das partes interessadas. }\end{array}$ \\
\hline $\begin{array}{l}\text { Orientação por } \\
\text { processos e } \\
\text { informações }\end{array}$ & $\begin{array}{l}\text { Compreensão e segmentação do conjunto das atividades e processos da orga- } \\
\text { nização que agreguem valor para as partes interessadas, sendo que a tomada } \\
\text { de decisão e execução de ações deve ter como base a mediação e análise do } \\
\text { desempenho. }\end{array}$ \\
\hline Visão de futuro & $\begin{array}{l}\text { Compreensão dos fatores que afetam a organização, seu ecossistema e o ambi- } \\
\text { ente externo no curto e no longo prazo, visando a sua perenização. }\end{array}$ \\
\hline Geração de valor & $\begin{array}{l}\text { Alcance de resultados consistentes, assegurando a perenidade da organização } \\
\text { pelo aumento de valor tangível de forma sustentada para todas as partes inter- } \\
\text { essadas. }\end{array}$ \\
\hline $\begin{array}{l}\text { Valorização das } \\
\text { pessoas }\end{array}$ & $\begin{array}{l}\text { Estabelecimento de relações com as pessoas, criando condições para que elas } \\
\text { se realizem profissionalmente e humanamente. }\end{array}$ \\
\hline $\begin{array}{l}\text { Conhecimento } \\
\text { sobre o cliente e } \\
\text { o mercado }\end{array}$ & $\begin{array}{l}\text { Conhecimento e entendimento do cliente e do mercado, visando à criação de } \\
\text { valor de forma sustentada para o cliente e, consequentemente, gerando maior } \\
\text { competitividade nos mercados. }\end{array}$ \\
\hline $\begin{array}{c}\text { Desenvolvimento } \\
\text { de parcerias }\end{array}$ & $\begin{array}{l}\text { Desenvolvimento de atividades em conjunto com outras organizações, a partir } \\
\text { da plena utilização das competências essenciais de cada uma. }\end{array}$ \\
\hline $\begin{array}{l}\text { Responsabili- } \\
\text { dade social }\end{array}$ & $\begin{array}{l}\text { Atuação que se define pela relação ética e transparente da organização com } \\
\text { todos os públicos com os quais se relaciona. }\end{array}$ \\
\hline
\end{tabular}

Fonte: FNQ (2008a, p. 7).

Os fundamentos da excelência são definidos, pelo FNQ (2008a), como os pilares de sustentação do modelo, a base teórica para a boa gestão, os quais devem ser internalizados à organização a partir da sua cultura, visto que sua implantação não ocorre de forma mecânica (FNQ, 2008a). 
Figura 1 - Modelo de Excelência da Gestão.

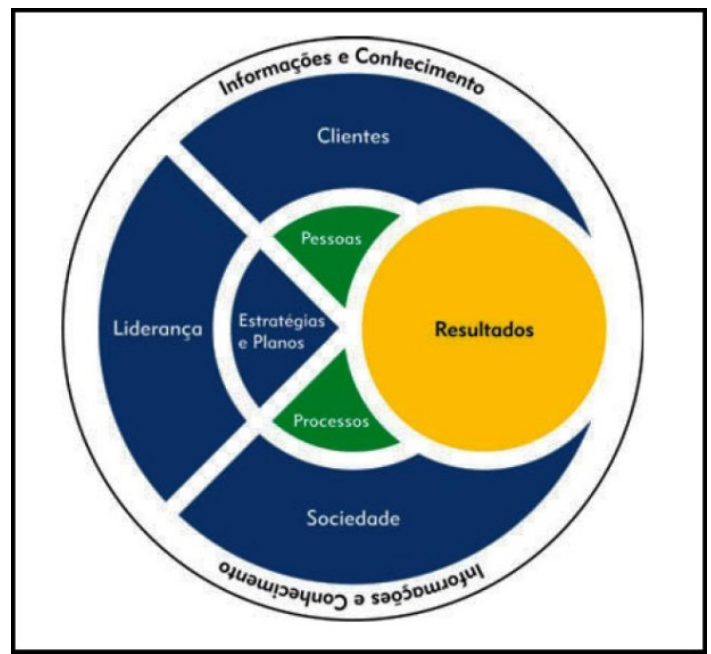

Fonte: FNQ (2008a, p. 10).

A prática dos fundamentos ocorre por meio de oito critérios, descritos como liderança, estratégias e planos, clientes, sociedade, informações e conhecimento, pessoas, processos e resultados, ilustrados na Figura 1.

O uso dos indicadores da FNQ é sugerido por França (2010) para avaliarem o desempenho da organização, os quais verificam os esforços para criar e manter um ambiente de trabalho e um clima organizacional adequados à excelência do desempenho, à participação e ao crescimento pessoal e organizacional. Gil (2009) e Vieira Filho (2003) explicam que a FNQ tem como objetivo reconhecer e premiar organizações bem-sucedidas no enfoque da qualidade e que os critérios de excelência do PNQ podem ser implantados pelas organizações para avaliarem seu estágio de excelência sem, contudo, sem haver a obrigatoriedade de se candidatarem ao Prêmio.

Este estudo tem foco o critério pessoas, que procura analisar como são proporcionadas as condições para o desenvolvimento e a plena utilização do potencial das pessoas (FNQ 2008b). O MEG atribui ao critério pessoas ênfase na força de trabalho organizacional, que se constituí por empregados diretos, mão de obra temporária, autônoma ou terceirizada, que estejam submissas à administração direta da organização, estagiários e aprendizes (FNQ, 2008b).

Este critério se baseia em quatro dos onze fundamentos do MEG que são: a valorização das pessoas, que proporciona meios para realização pessoal e profissional das pessoas; a geração de valor, pelo alcance de resultados que assegurem a longevidade organizacional; o pensamento sistêmico, que é o entendimento da interdependência entre os indivíduos, a organização e o macroambiente; e o aprendizado organizacional, pela busca e obtenção constante de maior grau de conhecimento (FNQ, 2008b).

A estruturação do critério pessoas ocorre em três divisões temáticas (FNQ, 2008b). O primeiro tema é o sistema de trabalho, composto pelas atividades de gestão de pessoas voltadas ao recrutamento e seleção; integração, cooperação e comunicação eficaz; organização das pessoas; avaliação de desempenho; remuneração, reconhecimento e incentivos. A temática de sistemas de trabalho evidencia os fundamentos de geração de valor e de aprendizado organizacional ao direcionar a organização para a avaliação de desempenho, recompensa e remuneração como impulsionadores para a cultura da excelência pelo elevado desempenho organizacional (FNQ, 2008b). 
Segunda divisão temática proposta pela FNQ (2008b), a capacitação e desenvolvimento se apoiam nos fundamentos de valorização das pessoas e de aprendizado organizacional, alinham os esforços de capacitação e desenvolvimento, e oportunizam aos colaboradores o desenvolvimento profissional e humano. O desenvolvimento integral abrange a área profissional, por meio do crescimento na carreira, na ocupação de postos de trabalhos mais complexos e com maior responsabilidade, resultando na satisfação profissional, melhor remuneração e reconhecimento (FNQ, 2008b). Para este desenvolvimento integral acontecer, soma-se a prática de orientação feita pela empresa, que apoia e recomenda ações para a tomada de decisão relativa à carreira do colaborador, por meio da atuação do indivíduo na organização e dos apontamentos das avaliações de desempenho (FNQ, 2008b).

O terceiro tema que estrutura o critério pessoas é a qualidade de vida, colocada em prática por meio da saúde ocupacional, segurança e ergonomia, bem como por meio da busca do bemestar e da motivação dos indivíduos. A FNQ (2008b) reforça a importância dessa temática para que as pessoas usem plenamente as suas capacidades em favor da organização, gerando equipes de alto desempenho e possibilitando a retenção de colaboradores talentosos.

Temas como governança corporativa e liderança influenciam diretamente a QVT (FNQ, 2008b, p.24), cujas ações e interação com a força de trabalho influenciam o clima organizacional e as conclusões da análise de desempenho, que devem ser utilizadas para a correção dos rumos que norteiam os processos de QVT. A implementação das estratégias deve abranger os processos relativos a QVT, comparar os benefícios, políticas e programas de pessoas com o praticado no mercado,os ativos intangíveis - as pessoas - devem ser desenvolvidos, protegidos e exercer influência nos processos relacionados à QVT (FNQ, 2008b).

\section{Procedimentos Metodológicos}

Para responder às questões deste estudo realizou-se uma pesquisa descritiva com o intuito de examinar e descrever o comportamento e as características dos fenômenos, bem como identificar e disponibilizar informações de um problema (COLLIS; HUSSEY, 2005), com abordagem qualitativa, pela necessidade de entendimento do fato ou fenômeno estudado, com base na opinião dos entrevistados (VERGARA, 2009).

Optou-se por um estudo de caso, por se tratar de uma pesquisa com questões do tipo "como" e "por que", bem como pela necessidade de se destacar um fenômeno contemporâneo no contexto da vida real (YIN, 2010). O roteiro de entrevista utilizado nesta pesquisa foi o modelo de excelência em gestão na dimensão pessoas contendo 14 perguntas, e seu critério de avaliação por itens desenvolvidos pela Fundação Nacional de Qualidade. Para analisar o critério Pessoas, o modelo de excelência em gestão propõe a avaliação dos processos gerenciais dos seguintes temas: sistemas de trabalho, por meio de cinco perguntas, capacitação e desenvolvimento, com quatro questões, e qualidade de vida com um roteiro de cinco perguntas. Os sujeitos desta pesquisa são os gestores de pessoas das empresas pesquisadas.

A escolha das organizações participantes, no que se refere ao porte e modelo de gestão, teve como fator determinante a conveniência no acesso às empresas e seus gestores de pessoas. Todas atuam no mercado da construção civil estão inseridas em um mesmo contexto econômico, político e mercadológico, e tem suas sedes no norte paranaense. Com o intuito de manter a identidade das empresas preservada, as mesmas serão identificadas pelos nomes Alfa, Ômega e Sigma. A amostra intencional, utilizada neste estudo, é o tipo mais comum, na qual o interesse do pesquisador reside em determinado elemento da população, não representativo desta (MARCONI; LAKATOS, 2002).

Para definir o porte das empresas de construção civil, Teixeira (2003) esclarece que a 
Câmara Brasileira da Indústria da Construção (CBIC) orienta-se pelo número de empregados, por ser este o critério mais utilizado pelas legislações e organismos oficiais, adotado pelo Serviço Brasileiro de Apoio às Micro e Pequenas Empresas (SEBRAE). Segundo a autora, são consideradas de pequeno porte as construtoras que empregam entre 20 e 99 trabalhadores, as de médio porte aquelas que possuem entre 100 e 499 empregados trabalhando e as de grande porte as que empregam a partir de 500 colaboradores. Assim, considera-se a Alfa uma empresa de grande porte, a como de Ômega médio porte e a Sigma como de pequeno porte.

\section{Análise dos Resultados}

Neste capítulo apresentam-se a análise dos dados com intuito de responder os objetivos propostos neste estudo, dividida nas categorias sistema de trabalho, capacitação e desenvolvimento e qualidade de vida.

\section{Categoria de Análise - Sistemas de Trabalho}

A categoria sistemas de trabalho refere-se à forma de organização das pessoas, de modo a estimular a resposta rápida e o aprendizado organizacional, com destaque aos aspectos importantes ao pleno uso dos potenciais individuais, tais como a forma de interação entre as pessoas e a divisão de tarefas e de responsabilidades (FNQ, 2009).

Em resposta ao primeiro questionamento, sobre como se dão a elaboração e a implementação da organização do trabalho com vistas ao alinhamento com o modelo do negócio, a gestora de pessoas do grupo Alfa afirma: o RH dispõe de missão e visão, bem como de valores que se orientam pelos valores da companhia. Trabalhamos com a melhoria contínua dos processos, com políticas bem definidas, políticas de remuneração e políticas de benefícios. Na Ômega, a elaboração do sistema de trabalho ocorre, segundo seu gestor de pessoas: pela integração via sistema informatizado, com a integração entre os recursos humanos, o financeiro, o contábil e os suprimentos. Toda a comunicação ocorre em tempo real, com a mínima utilização de papel, e-mail e telefone, registrando no sistema todas as ocorrências.

A gestora de pessoas da empresa Sigma, por sua vez, declara que: tudo começa com a contratação, o candidato precisa estar conectado com a missão, a visão e valores, [...] senão ele não consegue se adaptar à empresa. Verifica-se que os discursos dos gestores vão ao encontro dos pensamentos de (LACOMBE, 2005) para quem a área de gestão de pessoas tem o papel de apoio aos gerentes das diversas áreas para atendimento da demanda dos setores por "profissionais responsáveis e comprometidos, essenciais ao desenvolvimento de competências dos colaboradores" (ROCHA-PINTO et al., 2007, p. 67), bem como por um ambiente favorável à criatividade e implantação de novas ideias que atribui competitividade a organização (FNQ, 2008c).

Quando questionados sobre como as pessoas são selecionadas, interna e externamente, e contratadas em consonância com as estratégias e as necessidades do modelo de negócio da organização. A gestora de pessoas do grupo Alfa revela: a busca sempre é por colocar a pessoa certa no lugar certo Ela explica, ainda: além de ser um bom profissional, o candidato deve enquadrar-se ao perfil, demonstrar durante o processo seletivo o conhecimento e as habilidades específicas para a posição para a qual concorre. Tal procedimento acompanha a filosofia de trabalho de França $(2010$, p. 3), ao defender que o recrutamento "se faz com base nas requisições de pessoal emitidas pelos supervisores".

O gestor de pessoas da Ômega esclarece: primeiro se avalia o nível técnico do candidato, [...] e depois a necessidade do complemento de quadro. Ao discorrer sobre o processo de seleção e contratação, Almeida et al. (2009) destacam que estes processos respeitam a cultura 
da organização, por ser ela o elemento que permite que a organização encontre formas de adaptação e integração ao entorno para sua sobrevivência. A gestora de pessoas da empresa Sigma, por sua vez, explica: realizamos um processo para os operários que envolvem dinâmicas, com o objetivo de entender a experiência e competência técnica dos candidatos. No discurso da gestora da Sigma, identificam-se fragmentos da teoria de Rocha-Pinto et al. (2007), para quem o processo de captação e seleção de talentos é um procedimento com vistas a atrair e contratar pessoas adequadas.

A terceira pergunta da categoria busca explicações como as pessoas recém-contratadas são integradas a cultura organizacional visando prepará-las para o pleno exercício das suas funções. A gestora de pessoas do grupo Alfa afirma: todos os novos colaboradores são submetidos, de forma individualizada, a um dia de integração institucional com apresentação formal no escritório, depois na obra e na central de decorados. Verifica-se que a gestora de pessoas do grupo Alfa segue os conceitos de Araújo (2006), ao defender que finalizada a etapa de seleção, a gestão de recursos humanos inicializa o processo de integração, que caracteriza o início do programa de integração e culmina na socialização dos novos funcionários.

O gestor de pessoas da Ômega, por sua vez, informa: inicialmente, o novo empregado conhece o canteiro de obras e o espaço para o seu exercício profissional, acompanhado por um técnico de segurança do trabalho que adverte quais os cuidados. O discurso do gestor revela a importância que a empresa atribui ao processo de conscientizar as pessoas da empresa sobre a política da qualidade, o negócio e a visão organizacionais (VIEIRA FILHO, 2003, p. 94). A gestora de pessoas da Sigma declara: no primeiro de dia de trabalho acontece a integração onde explico os valores e a missão, a visão da empresa e o que se espera com a vinda do contratado. O discurso da gestora vai ao encontro dos pensamentos de Levy Jr. (1973), para quem a socialização é um processo contínuo no qual o indivíduo identifica hábitos e valores característicos que o ajudam no desenvolvimento de sua personalidade e na integração de seu grupo.

Percebe-se que todas as empresas pesquisadas preocupam-se em integrar de seus colaboradores entrantes à cultura da organização. Esta prática é consoante à definição dada por Schein (2001, p.178) que afirma ser a cultura "produto do aprendizado social, e as maneiras de pensar e agir compartilhadas que funcionam, acabam se tornando elementos de cultura".

Avançando para a avaliação de desempenho, perguntou-se aos três gestores como o desempenho das pessoas e das equipes é avaliado de modo a estimular a obtenção de metas de alto desempenho, a cultura da excelência na organização e o desenvolvimento profissional das mesmas. Por entender a avaliação de desempenho como um meio de se aumentar a competência dos colaboradores (FRANÇA, 2010), a gestora do grupo Alfa revela: o processo começa pela cultura do feedback e está sendo exercitado, inicialmente, entre os diretores e gerentes para identificar suas principais competências, e por meio de bate-papos anuais entre líderes e liderados com o mesmo objetivo.

O gestor de pessoas da empresa Ômega relata: quando da contratação, já é feita uma pré-avaliação da aptidão para exercer aquela função, [...] tem sempre uma avaliação técnica em cima do desempenho. Deste modo, segundo o gestor de pessoas, o colaborador tem liberdade para trabalhar e crescer e, assim, contribuir para que os objetivos da empresa se realizem. A gestora de pessoas da Sigma afirma: trabalhamos junto à liderança quando o assunto é desempenho de equipe porque se você não tem uma liderança muito focada no alinhamento da empresa, uma comunicação muito clara, eu acho que a gente não consegue ter o alto desempenho da equipe. O sistema de avaliação de desempenho, quando implantado formalmente, na visão de Gil (2009), proporciona maior nível de profundidade, racionalidade e não permite superficialidade, partidarismo e distorção. Percebe-se nos discursos dos gestores 
de pessoas da Ômega e da Sigma que a avaliação de desempenho ocorre informalmente nas empresas.

O quinto e último questionamento do tema sistemas de trabalho busca compreender como a remuneração, o reconhecimento e os incentivos que estimulam o alcance das metas de alto desempenho e a cultura da excelência. A gestora de pessoas do grupo Alfa revela: anualmente ocorre uma reavaliação dos cargos e faixas salariais e prováveis promoções em toda a empresa, podendo também acontecer no decorrer dos meses de forma específica. Ela explica que estas práticas acabam por motivar a equipe e aumentar o grau de satisfação deles.

Ao reconhecer a necessidade de manter a satisfação e motivação dos colaboradores pela prática do reconhecimento (ROCHA-PINTO et al., 2007), o grupo Alfa executa estas ações por meio de promoções e, conforme as metas de departamentos são atingidas ocorrem celebrações, prática incentivada pela empresa, mas não formalizada e não engessada, que considera "aspectos particulares de cada indivíduo no tocante a sua singularidade, a sua subjetividade" (CAVALCANTI, 2009, p. 86).

Atualmente existem formas de reconhecimento que não remetem a valor financeiro e que visam à manutenção da motivação e da autoestima do profissional (ROCHA-PINTO et al., 2007). Nesse sentido, o gestor de pessoas da empresa Ômega declara: o que nós primamos é a questão da liberdade, é a filosofia da empresa ao declarar existir um ambiente livre para trabalho [...] sem uma cobrança excessiva, onde o funcionário tem a liberdade para crescimento pessoal e moral para ele, com certeza será bem alto o desempenho dele.

$\mathrm{Na}$ Sigma, a gestora de pessoas informa: a remuneração aqui na empresa seria o piso salarial. Nós temos alguns benefícios que é interessante para eles né e, principalmente, um programa de desenvolvimento profissional. A gestora explica, ainda: existe uma tabela salarial, uma avaliação de desempenho que o RH sempre está focado junto ao líder, e o líder com o liderado, então a gente sempre está lá avaliando pra que a gente possa também valorizar o funcionário, e o desempenho pelo reconhecimento. Tal procedimento se alinha ao entendimento de que o gestor de pessoas agrega um papel motivador ao cargo e deve atentar-se às necessidades dos indivíduos (GIL, 2009) e de que os líderes podem estimular e provocar a motivação em seus colaboradores (CAVALCANTI, 2009).

\section{Categoria de Análise - Capacitação e desenvolvimento}

Os temas capacitação e desenvolvimento referem-se às praticas com vistas a tornar o colaborador capaz para suas responsabilidades profissionais bem como proporcionar evolução deste para atividades mais complexas no futuro (FNQ, 2008b). A primeira questão aplicada aos entrevistados objetiva entender como são identificadas as necessidades de capacitação e desenvolvimento das pessoas, visando ao êxito de estratégias, a formação da cultura de excelência e a melhoria do desempenho individual.

A gestora de pessoas do grupo Alfa explica: próximo ao orçamento anual da gestão de pessoas se verifica com todos os líderes das possíveis necessidades de treinamento considerando as metas de sua área. O gestor de pessoas da Ômega compartilha: desde o manuseio de uma furadeira ou de um equipamento mais pesado, todo e qualquer equipamento que vá ser manuseado, ele (o funcionário) é treinado. No caso da Sigma, a gestora explica: eu tenho um programa de desenvolvimento de treinamento mais específico junto com o líder, mais técnico e comportamental, pra que ele se torne mais comprometimento e aprenda a se comunicar adequadamente com sua equipe.

Os gestores de pessoas das organizações pesquisadas, por meio de estratégias corporativa e competitiva definidas e claras, investem na ampliação do capital intelectual de 
suas organizações (LIMA, 2010), por meio de programas de treinamentos que buscam suprir habilidades, regras, conceitos e atitudes para que os colaboradores desempenhem bem suas tarefas (GIL, 2009).

A segunda pergunta da temática de Capacitação e desenvolvimento objetiva desvendar como é concebida a forma de realização dos programas de capacitação e desenvolvimento, considerando-se as necessidades da organização e das pessoas.

A função estratégica da gestão de pessoas busca suprir as necessidades institucionais, atuais e futuras (ALMEIDA et al., 2009). Seguindo este pressuposto, a gestora de pessoas do grupo Alfa afirma: para novos líderes ou pessoas que tenham um desafio muito grande para o próximo ano, existe o projeto Coaching, que é um treinamento individualizado onde é definido, com o líder e com o colaborador, quais são as metas que ele tem que desenvolver relacionadas a comportamento, para o próximo ano.

O gestor de pessoas da empresa Ômega revela: eu tenho um programa de treinamento onde eu trago pessoas de fora para poder trabalhar em cima disso, não só pessoas de fora, mas o RH, ou mesmo o líder também. A FNQ (2008b) explica que capacitação e desenvolvimento se apoiam nos fundamentos de valorização das pessoas e de aprendizado organizacional, alinham os esforços de capacitação e desenvolvimento, e oportunizam aos colaboradores o desenvolvimento profissional e humano. A gestora de pessoas da Sigma afirmou que a empresa não desenvolve programas de capacitação e desenvolvimento de seus colaboradores. Assim, verifica-se que a empresa não adota os princípios defendidos pela $\mathrm{FNQ}$.

Ao buscar entender como a eficácia dos programas de capacitação é avaliada em relação ao alcance dos objetivos estratégicos e operacionais da organização. No grupo Alfa existe uma avaliação de eficácia que se repete semestralmente. Segundo a gestora de pessoas do grupo, a avaliação consiste em: uma entrevista com o líder para ele dizer o que ele percebeu de melhoria nos resultados, efetivamente. Tal avaliação está contida no programa de gestão da qualidade da organização, integrante da política de recursos humanos. Assim, analisa-se que a eficácia do processo de desenvolvimento da Alfa segue os preceitos de França (2010), para quem o processo de desenvolvimento visa aperfeiçoar as capacidades e as motivações dos colaboradores de forma contínua e em longo prazo.

O gestor de pessoas da Ômega explicou: como nossos treinamentos se concentram no canteiro de obras, percebemos se ele foi eficaz quando o custo de manutenção dos equipamentos for baixo ou reduzido. As da Sigma relata: é eficaz quando percebo muita redução [...] de turnover, de absenteísmo e de faltas. Verifica-se, no discurso dos gestores da Ômega e Sigma, que a eficácia do processo de desenvolvimento vai de encontro da visão de Lacombe (2005), a qual a avaliação de desempenho objetiva proporcionar a melhoria no desempenho do colaborador no posto que ocupa.

Ao questionar-se como a organização promove o desenvolvimento integral das pessoas como indivíduos, cidadãos e profissionais. Por entender que os colaboradores podem ser estimulados e trabalhados em sua autoestima pelo compartilhamento do seu conhecimento e habilidades (ROCHA-PINTO et al., 2007), no grupo Alfa ocorre o estímulo ao "ser voluntario". A gestora explica: em cada região de atuação da organização, adota-se uma entidade que necessite de auxílio. Estimulamos o envolvimento dos colaboradores em ações sociais que extrapolem os muros da empresa. Ela afirma, também: gostamos quando nossos funcionários compartilham do seu tempo, do seu olhar e da sua expertise com instituições carentes.

O gestor de pessoas da Ômega afirma: promovemos a integração dos funcionários de obra com os funcionários da área administrativa através de eventos periódicos, o que corrobora o princípio da dignidade humana no que concerne à igualdade (PEDUZZI, 2009) com o foco no ser e não no ter. A gestora de pessoas da empresa Sigma enfatiza: essa questão tem 
relação com o comportamento da pessoa. Se um funcionário demonstre interesse em crescer profissionalmente e pessoalmente, a gente dá oportunidade. Deste modo, verifica-se na Sigma o respeito e o tratamento humano, visto que "pelo princípio da dignidade humana o individualismo patrimonial é suplantado pelo desenvolvimento da pessoa" (RACY, 2011, p. $62)$.

\section{Categoria de Análise - Qualidade de vida}

Na categoria Qualidade de Vida, a FNQ (2008b) foca a necessidade de retenção de talentos pela organização, bem como a manutenção do clima organizacional favorável ao alto desempenho das equipes, somando a esta categoria de análise a manutenção de práticas que garantam a integridade física das pessoas pela observância da saúde ocupacional, segurança e ergonomia.

Neste item de análise, inicia-se a entrevista investigando como são identificados os perigos e tratados os riscos relacionados à saúde ocupacional e a segurança na empresa.

O grupo Alfa, por meio de sua gestora de pessoas, afirma atender às exigências legais quanto ao Programa de Controle Médico de Saúde Ocupacional (PCMSO), ao Programa de Prevenção dos Riscos Ambientais (PPRA) e aos exames médicos periódicos que ocorrem anualmente. Com o intuito de melhorar seu desempenho nessa área, a gestora da Alfa afirma: criamos recentemente uma coordenação de segurança do trabalho para revisar toda a política e focar onde temos maior demanda de melhorias dentro da organização. Deste modo verificase que a empresa respeita a integridade física do indivíduo pela prevenção dos riscos laborais (CAMPOS, 2004), bem como pela medicina preventiva (ARAÚJO; SANTOS; MAFRA, 2006) o grupo incentiva e possibilita, de forma equitativa em todas as regionais, a prática da ginástica laboral no ambiente corporativo.

Por entender que a saúde do trabalho objetiva a promoção adequada de condições ambientais, o controle dos fatores causadores das doenças (ARAÚJO, 2006) e a garantia do bem-estar físico, mental e social dos trabalhadores (ARAÚJO; SANTOS; MAFRA, 2006), o gestor de pessoas da empresa Ômega afirma: temos uma parceria junto ao SINDUSCON que através do Serviço Social do Sindicato da Indústria da Construção Civil (SECONCI) presta toda a assessoria quanto aos programas médicos ocupacionais. Verifica-se a preocupação da Sigma em antecipar, reconhecer, avaliar e controlar os riscos existentes ou que venham a existir (ARAÚJO, 2006), por meio do discurso de sua gestora de pessoas: instituímos a Comissão Interna de Prevenção de Acidentes (CIPA), onde os integrantes se reúnem mensalmente para identificar problemas e situações graves que podem ocorrer, antecipando sua solução por meio da prevenção.

O segundo ponto que a categoria Qualidade de Vida busca esclarecer é como as necessidades e expectativas das pessoas da força de trabalho e do mercado de trabalho são identificadas, analisadas e utilizadas para o desenvolvimento de políticas e programas de pessoal e dos benefícios a elas oferecidas. A gestora de pessoas da Alfa declara: temos a cultura de utilizar, muito, a Semana Interna de Prevenção de Acidentes de Trabalho (SIPAT), onde procuramos envolver também a família do colaborador. Ela explica que ocorrem "palestras sobre administração da sua remuneração, como não se endividar; a gente vai se aprimorar mais quando a gente tiver esse perfil mais detalhado, o que favorece o desenvolvimento de um clima harmonioso no trabalho".

O gestor de pessoas da Ômega declara: as dificuldades enfrentadas dentro do ambiente profissional ou dentro do ambiente familiar são conhecidas, analisadas e trabalhadas para que nossos funcionários trabalhem de maneira mais confortável. A Sigma reforça, por meio do discurso de sua gestora de pessoas, que: sua ferramenta de pesquisa de clima e de 
satisfação tem um resultado bem interessante em seu uso. Mencionou-se, também: utilizo as ocorrências de reclamações, turnover e absenteísmo como fatores que acusam quando algo não está bem e proporcionam aos gestores trabalhar em sua causa. Verifica-se, por meio do discurso dos gestores, que as empresas pesquisadas buscam desenvolver um clima favorável ao pleno exercício das funções dos empregados.

Destaca-se que a gestora de pessoas do grupo Alfa revelou utilizar a pesquisa sobre o clima, prática essa confirmada pela gestora de pessoas da empresa Sigma, o que é consoante à visão de França (2010), quando descreve ser essencial na avaliação do clima organizacional abordar o estilo de liderança, a flexibilidade organizacional, o repeito, a confiança, a cooperação e a harmonia entre as pessoas, fatores que influenciam diretamente na satisfação, bem estar e comprometimento das pessoas. O gestor de pessoas da empresa Ômega, por sua vez, informou que isso ocorre pelo contato direto com os funcionários.

Ao buscar desvelar como as organizações procedem para a manutenção de um clima organizacional favorável a criatividade, a inovação, a excelência no desempenho e ao desenvolvimento profissional das pessoas e das equipes. Por entender que a resolução participativa dos problemas é elemento essencial da QVT (GIL, 2009) a gestora de pessoas do grupo Alfa focou um dos valores declarados pela organização, a gestão participativa que, segundo ela: ocorre pela manutenção de canais de comunicação que permitem sugestões.

Ao considerar que o clima é favorecido pela imposição de desafios e o enriquecimento das tarefas, atribuindo-lhes aos colaboradores maior grau de complexidade (PILATTI, 2012) verifica-se, por meio do discurso do gestor de pessoas da Ômega que: é através do desenvolvimento e de mudança dos processos, do crescimento dentro de cada setor, dentro de cada atividade, que se desenvolve e se mantém um clima agradável na empresa e também acontece o desenvolvimento do pessoal.

Ao responder sobre manutenção de clima, a gestora de pessoas da empresa Sigma afirma: a gente precisa falar também da informação e comunicação interna, o que é defendido por França (2010) ao afirmar que a eficácia da comunicação interna está contida na avaliação do clima organizacional. A gestora explica: a empresa dispõe de algumas ferramentas de comunicação na obra como, por exemplo, o mural [...] e cartazes com o trabalho que precisa ser feito com vistas ao efetivo alinhamento e comprometimento.

Para finalizar a categoria de análise Qualidade de Vida, bem como o roteiro de entrevista elaborado pela FNQ, tem-se a indagação: como a organização colabora com a melhoria da qualidade de vida das pessoas fora do ambiente de trabalho?

Segundo a gestora de pessoas do grupo Alfa: isso ocorre através da comunicação, da conscientização e também da geração de renda, quando a empresa tá indo bem, consequentemente as pessoas também vão bem. Assim, ocorre a manutenção do emprego de cada colaborador. Esta visão corrobora com a conexão que França (2010) faz entre QVT e a ética da condição humana, que remete ao principio constitucional do direito ao trabalho e à dignidade da pessoa humana.

Como os benefícios percebidos pelos funcionários, bem como o relacionamento interpessoal e sua humanização influenciam diretamente na QVT (SCHNEIDER; CARNEIRO; FIATES, 2009), na empresa Ômega a melhoria da qualidade de vida das pessoas fora do ambiente de trabalho ocorre, segundo seu gestor de pessoas: pelo fornecimento dos planos de saúde, o plano odontológico, convênio de farmácia que também engloba toda a família, pela realização de eventos periódicos que integram funcionários e famílias.

Atualmente a empresa Sigma realiza palestras para os funcionários das obras, visando à conscientização de temas como o consumo de bebida alcoólica e outras drogas, uma vez que sua gestora de pessoas afirma haver na empresa, um alto índice de ocorrências. A gestora 
afirma: o RH tem uma facilidade muito grande de chegar até o funcionário e conversar realmente o que está acontecendo, o que a gente pode fazer para ajudar. As ações empregadas pala Sigma favorece a aplicação de fatores envolvidos pela QVT e "colocá-los em prática retornam em novos patamares de qualidade para a organização” (GIL, 2009, p. 106).

\section{Considerações Finais}

O Modelo de Excelência em Gestão na dimensão pessoas procura analisar como são proporcionadas as condições para o desenvolvimento e a plena utilização do potencial das pessoas (FNQ 2008b). Ao se analisar como os processos gerenciais são aplicados na gestão de pessoas em empresas do setor da construção civil do norte paranaense, verifica-se que no grupo Alfa a melhoria contínua na organização do trabalho ocorre por meio da utilização de ferramentas específicas dentro do processo de recrutamento e seleção, bem como a promoção da capacitação e desenvolvimento acontece por meio do programa de educação continuada, da proatividade na preparação de líderes e de outros profissionais frente às demandas futuras bem como a reciclagem por meio do programa de coaching. Nos processos gerenciais da empresa Ômega, a melhoria continua na organização do trabalho se verifica por meio da liberdade de trabalho e da autonomia de cada colaborador dentro de sua função, bem com na integração de todos os setores da organização via sistema informatizado. Verifica-se, ainda, que apesar dos colaboradores da empresa Ômega contarem com a possibilidade de crescimento, não ocorre o desenvolvimento das pessoas, apenas a capacitação. A empresa Sigma, por sua vez, utiliza relatórios com os índices de absenteísmo, rotatividade e disponibilidade para trabalhos extraordinários como balizador do bom andamento das relações entre as pessoas, bem como sua pesquisa de clima organizacional.

Quanto a compreender como o sistema de trabalho é elaborado e implementado pela organização, analisa-se que as empresas demonstraram o trabalho como elaborado com vistas ao crescimento dos colaboradores, os canais de comunicação existentes são bem explorados, as empresas possibilitam a participação de todos nos processos de melhorias, bem como existe o compartilhamento da cultura organizacional desde o ingresso dos empregados.

No que tange a verificar como ocorrem os processos de capacitação e desenvolvimento dentro da organização analisa-se que os processos desenvolvidos pelas empresas pesquisadas, sejam eles formais ou não, favorecem a participação dos líderes e das próprias pessoas na capacitação e desenvolvimento da equipe.

Ao se desvelar como a qualidade de vida é praticada na organização pesquisada, verificase que os procedimentos relativos à saúde ocupacional e à segurança, aos benefícios e subsídios que disponibilizam aos colaboradores, bem como aos fatores que afetam o bem estar, a satisfação e o comprometimento das pessoas, possuem ações direcionadas tanto aos colaboradores quanto a seus familiares, exceto na empresa Sigma, que não pratica ações com alcance dos familiares.

Futuros estudos poderão ser empreendidos utilizando o Modelo de Excelência da Gestão nas demais dimensões, o que pontuará o direcionamento dos esforços para a melhoria dos processos gerenciais atribuindo competitividade às organizações.

Ao aplicar o modelo de excelência em gestores de pessoas nas empresas pesquisadas, verificaram-se os esforços para criar e manter um ambiente de trabalho e um clima organizacional adequados a excelência do desempenho, que implicam na participação e no crescimento pessoal e organizacional. Considera-se, ainda, que a valorização das pessoas nas empresas pesquisadas proporciona meios para realização pessoal e valor para a organização, por meio do alcance de resultados que assegurem sua longevidade. 


\section{REFERÊNCIAS BIBLIOGRÁFICAS}

ALMEIDA, Walnice Maria da Costa de; FAISSAL, Reinaldo; PASSOS, Antônio Eugênio Valverde Mariani; MENDONÇA, Márcia da C. Furtado de. Atração e seleção de pessoas. 2. ed. Rio de Janeiro: Editora FGV, 2009.

ARAÚJO, Luís César G. de. Gestão de Pessoas: estratégias e integração organizacional. São Paulo: Atlas, 2006.

ARAÚJO, Renata Pereira de; SANTOS, Neri dos; MAFRA, Wilson José. Gestão da segurança e saúde do trabalho. III SEGeT - Simpósio de Excelência em Gestão e Tecnologia. Rio de Janeiro, 2006.

CAMPOS, Armando Augusto Martins. Modelo estratégico de gestão de segurança e saúde no trabalho. Niterói: Universidade Federal Fluminense, 2004. 161 p. Dissertação (Sistemas de Gestão) Universidade Federal Fluminense

CAVALCANTI, Vera Lucia; CARPILOVSKY, Marcelo; LUND, Myrian; LAGO, Regina Arczynska. Liderança e motivação. 3. ed. Rio de Janeiro: Editora FGV, 2009.

CÓDIGO DE ÉTICA: Plaenge, Plaenge Chile, Vanguard Home e Emisa. Edição 2012. Disponível em <http://www.plaenge.com.br/UPLOAD/lmgConteudos/1656.pdf>. Acesso em01.out.2012.

COLLIS, Jill; HUSSEY, Roger. Pesquisa em administração: um guia prático para alunos de graduação e pós-graduação. 2 ed. Porto Alegre: Bookman, 2005.

DIAS, Reinaldo. Cultura organizacional. Campinas: Alínea, 2003.

FLEURY, Maria Tereza Leme. Estórias, mitos, heróis: cultura organizacional e relações do trabalho. Artigo de livre docência. Revista de Administração de Empresas. Rio de Janeiro, 1987.

FRANÇA, Ana Cristina Limongi. Práticas de recursos humanos - PRH: conceitos, ferramentas e procedimentos. São Paulo: Atlas, 2010.

FUNDAÇÃO NACIONAL DA QUALIDADE (FNQ). Cadernos de Excelência: Introdução ao Modelo de Excelência da Gestão. São Paulo: FNQ, 2008a.

FUNDAÇÃO NACIONAL DA QUALIDADE (FNQ). Cadernos de Excelência: Pessoas. São Paulo: FNQ, 2008b.

FUNDAÇÃO NACIONAL DA QUALIDADE (FNQ). Cadernos de Excelência: Conceitos fundamentais da excelência da gestão. São Paulo: FNQ, 2008c.

FUNDAÇÃO NACIONAL DA QUALIDADE (FNQ). Critérios de Excelência 2010. São Paulo: Fundação Nacional da Qualidade, 2009.

GIL, Antônio Carlos. Gestão de pessoas: enfoque nos papéis profissionais. São Paulo: Atlas, 2009.

KNAPIK, Janete. Gestão de Pessoas e Talentos. 2. ed. Curitiba: Ibpex, 2008.

LACOMBE, Francisco José Masset. Recursos humanos: princípios e tendências. São Paulo: Saraiva, 2005.

LEVY Jr., Maurício. Socialização. In: CARDOSO, F. H.; IANNI, O. (Orgs.). Homem sociedade. São Paulo: Editora Nacional, 1973.

LIMA, Débora Cristina Sardelli de. A relação entre treinamento e desenvolvimento de Pessoas e prioridades competitivas da manufatura: um estudo de caso em empresa de autopeças. 2010. 81 p. Dissertação de Mestrado em Engenharia de Produção - Faculdade de Engenharia, Arquitetura e Urbanismo da Universidade Metodista de Piracicaba. Santa 
Bárbara d' Oeste, 2010.

MARCONI, Marina de Andrade; LAKATOS, Eva Maria. Técnicas de pesquisa: planejamento e execução de pesquisas, amostragens e técnicas de pesquisas, elaboração; análise e interpretação de dados. 5 ed. São Paulo: Atlas, 2002.

MINISTÉRIO DO DESENVOLVIMENTO, INDÚSTRIA E COMÉRCIO EXTERIOR (MDIC). O futuro da Construção Civil no Brasil: Resultados de um estudo de prospecção tecnológica da cadeia produtiva da construção habitacional. São Paulo: MDIC, 2003

PEDUZZI, Maria Cristina Irigoyen. O princípio da dignidade da pessoa humana e sua eficácia concreta. Revista do Tribunal Superior do Trabalho, Brasília, v. 75, n. 1, 2009.

PILATTI, Luiz Alberto. Qualidade de vida no trabalho e teoria dos dois fatores de Herzberg: possibilidades-limite das organizações. Revista Brasileira de Qualidade de Vida. v. 04, n. 1, 2012.

RACY, Vivien. Efetivação da dignidade da pessoa humana e as cláusulas gerais. Revista de Direito Privado. Ano 12, v. 47. São Paulo: Editora Revista dos Tribunais, 2011.

ROCHA-PINTO, Sandra Regina da; PEREIRA, Cláudio de Souza; COUTINHO, Maria Teresa Correia; JOHANN, Silvio Luiz. Dimensões funcionais da gestão de pessoas. Rio de Janeiro: Editora FGV, 2007.

RONCON, Aleksander; SOUSA, Tarcita Cabral Ghizoni; BELTRAME, Indiara; LAVARDA, Rosália Aldraci Barbosa. A Estratégia como Prática utilizada no Reconhecimento de um Curso de Graduação pelo Mec. Rev. Adm. UFSM, Santa Maria, v. 6, Edição Especial, p. 263-280, MAI. 2013.

SARTORI, Tatiane; SILUK, Júlio Cezar Mairesse. Modelo de excelência em gestão (MEG): aplicação em uma empresa de software de Santa Maria/RS. 2011. VIII Simpósio de Excelência em Gestão e Tecnologia.

SCHEIN, Edgar. H. Organization Culture and Leadership. San Francisco: Jossey-Bass, 1987.

. Guia de sobrevivência da cultura corporativa. Rio de Janeiro: José Olympio, 2001.

SCHNEIDER, Aline Botelho; CARNEIRO, Marcelo Lopes; FIATES, Gabriela Gonçalves Silveira. O recurso mais importante para as organizações são mesmo as pessoas? Uma análise da produção científica sobre QVT. 2009. II Encontro de Gestão de Pessoas e Relações de Trabalho. Curitiba, 2009.

TEIXEIRA, Gilnei Mourão; SILVEIRA, Aristeu Coelho da; NETO, Carlos Pinheiro dos Santos Bastos; OLIVEIRA, Gercina Alves de. Gestão estratégica de pessoas. Rio de Janeiro: Editora FGV, 2005.

TEIXEIRA, Luciene Pires. Definição de pequena e média empresa no setor da construção brasileira. Belo Horizonte: CEE/CBIC, 2003. Disponível em <http://www.cbicdados.com.br/ files/textos/011.pdf > Acesso em 07.mai.2012.

VERGARA, Sylvia Constant. Projetos e relatórios de pesquisa em administração. 11 ed. São Paulo: Atlas, 2009.

VIEIRA FILHO, Geraldo. GQT - Gestão da Qualidade Total: uma abordagem prática. Campinas: Alínea, 2003. 2010.

YIN, ROBERT K. Estudo de caso: planejamento e métodos. 4.ed. Porto Alegre: Bookman, 